\title{
Faculty Retraining: A Strategic Response to Changing Resources and Technology
}

\author{
Richard L. Alfred \\ Nancy S. Nash
}

An emerging problem in public community colleges is the need to retrain or revitalize faculty in career programs to improve the performance of the institution in relation to changing economic conditions, shifting labor market needs, and rapid advances in technology. Two basic trends are evident among two-year colleges throughout the United States as they attempt to cope with this problem. One trend involves planned change in the quality of programs through marketing techniques designed to produce selective growth in enrollments and staff. Addition of new staff to serve expanding numbers of students is a convenient method by which to improve the outputs of career programs because continuing faculty are protected by policies and collective bargining agreements which direct the flow of resources to fixed costs for salaries and benefits in current programs. Resistance to change in the program mix normally associated with entrenched faculty - particularly those in danger of being displaced to make way for new faculty -is essentially eliminated as change occurs through a process of addition with supplemental income used to maintain faculty in academic departments.

The second trend involves a greater element of risk insofar as program change is accomplished through a process of reallocation to divert resources from declining programs to high demand programs. Involving "high risk" administrative procedures such as program review and strategic planning, the "vitality" of academic programs is improved through a process of substitution, in which resources are redistributed among programs through non-replacement of selected faculty, selective hiring of new faculty, expansion or reduction of student/faculty ratios, and unilateral reduction of equipment and supply budgets. The effects of this approach are well documented in community colleges throughout the United States. Litigation is employed as a vehicle for protection of faculty teaching loads, early 
retirement procedures are developed to reduce institutional dependence on "high salaried" faculty, and an uncomfortable breech develops between administrators and faculty in courses and curricula targeted for reduction.

Both trends fail to address the issue of institutional adjustment to shifting or declining resources in community colleges through retraining of faculty. Change in the program structure through processes of "addition" and "substitution" is a worthwhile endeavor, but it serves to effectively avoid the problem of what to do with outdated or surplus faculty. Faced with dual conditions of declining resources and academic policies which preclude the arbitrary dismissal of full-time faculty without due process, community colleges have no choice but to consider faculty retraining as a method for improving institutional responsiveness to changing conditions in the labor market. Presented in this article is a model for faculty retraining in community college career programs keyed to the process of exchange of staff between industry and education to improve the quality of instruction in two-year colleges. The rationale for the model is one of exchange of staff between industry and community college education to improve institutional responsiveness to: 1) fluctuations in industry need for trained manpower and 2) changing conditions governing the supply of faculty in emerging high demand career fields such as business, allied health, and the engineering sciences. The article concludes with a statement of the advantages, both direct and indirect, offset to industry and community colleges through participation in the industry/education exchange program.

\section{Dynamic Flux in Programs and Faculty}

It is increasingly apparent that community college programs will be in a constant state of flux throughout the decade of the 80's. Occupational courses will change frequently and projections are increasingly common of horizontal transition in jobs such that within ten years, "one in three workers will be employed at jobs that do not exist today," (Lahti, 1977). Recently released national data show an increase in student interest in business, health, and engineering technologies (Cooperative Institutional Research Program, 1982). Between 1968 and 1981 student interest in professional and paraprofessional business, engineering, and allied health fields increased by approximately 100 percent to account for 51 percent of the total freshmen enrollment in colleges and universities in 1981. By way of contrast, enrollment in the humanities and social sciences decreased substantially between 1968 and 1981 to a level of 13 percent of the freshmen students enrolled in postsecondary institutions in Fall 1981.

If community colleges are to train for new jobs and changing patterns of student interest in career programs, new sources of faculty must be located and institutional procedures developed for the retraining of outdated faculty. Since most two-year colleges have in- 
corporated into policy academic procedures which prohibit the dismissal of full-time faculty without cause, retraining as a method for balancing student interests and industry needs with faculty instructional proficiency is a concept worthy of serious consideration.

\section{Extant Models for Faculty Retraining}

The literature on faculty retraining in higher education places a considerable emphasis on staff and faculty development in four-year colleges. Population projections showing fewer traditional age college students poses a critical problem for baccalaureate degree institutions prompting these colleges to expend resources on retraining tenured faculty for instruction in new fields. In community colleges the focus of retraining programs is on development and updating of instructional proficiency in high demand career curricula such as accounting, data processing, and engineering sciences. The general format for such programs includes released time for faculty to attend seminars and workshops, visitation agreements for observation of technical practices in private sector organizations, and provision of media and learning skills specialists for assistance in the preparation of course content materials. Voluntary participation of faculty in retraining programs is viewed as essential and active support fromfaculty peers in the academic department is a requisite if the program is to succeed.

A key problem in state-of-the-art faculty retraining programs is the difficulty encountered in encouraging faculty to update teaching skills if retraining includes the need to alter course content and teaching methodology. Faculty in technical disciplines cannot easily adapt to change in instructional content and methodology associated with changing technical applications in industry unless similarities exist between current and new approaches to instruction in career programs. This opens up the problem for community colleges of retraining faculty in career programs in which a major transition is required in instructional content and methodology to adapt to changing technology. To date, faculty retraining programs have achieved some measure of success in colleges and universities if some or all of the following provisions are implemented:

1. There is a clear understanding among faculty of the financial and labor market conditions which culminate in the need to retrain. Information relative to institutional finances and costs is openly shared between faculty and administration;

2. An atmosphere of collegiality and loyalty to the college prevails among faculty;

3. Funds are set aside specifically for faculty retraining. The college does not use staff development monies to supplement regular instructional salaries; and

4. Faculty involvement in retraining is targeted for implementation in course content areas closely related to the instructional proficiency of teaching faculty. 
Evidence of success attributed to current models for faculty retraining appears to be limited and sporadic. Programs are poorly conceived and implemented and result in participation by only a limited segment of the faculty-often those faculty with strong motivation who least used the retraining. Predicated exclusively on principles of volunteerism, inter-relationships of teaching strategies and technological change, and reciprocal support systems among faculty, current models are destined for failure unless a new model is proposed to successfully address looming problems of faculty participation and commitment, institutional resources, and benefits accruing to internal and external constituencies through retraining.

\section{Industry-Education Exchange Model}

Faculty retraining programs keyed to the involvement of organizations external to the community college offer considerable potential for success with respect to retraining faculty in occupational and technical curricula. Based on the premise that a lag exists between the manpower needs and technological sophistication of industry and the faculty who teach in occupational/technical programs, community colleges can forge linkages with business and industry to retrain and revitalize faculty in programs undergoing technological change. Labeled the "industry/education exchange model," faculty selected for retraining in career programs can be placed in business and industrial settings for a six- to twelve-month period to learn new skills, validate theory, study current practices, and learn problemsolving techniques. Simultaneous with the placement of faculty in business and industrial settings, would be placement of industry professionals and technicians in community college programs to plan, evaluate, and modify occupational curricula in accord with changing technology.

The essential components of the industry-education exchange model divide the responsibility for retraining between the community college, business and industry, and functions shared by both organizations. Retraining is viewed as an institutional need and an industry responsibility.

A typical "cycle" for the industry-education exchange program would be an annual program of activity with responsibility for specific functions divided between industry and education:

College Functions. The retraining cycle would begin with the establishment of program goals and objectives in yearly time frames by community college faculty and administrators. Desired outcomes of instruction would be specified in measureable terms for each program and faculty training and retraining activities to achieve specified goals would be determined during this phase.

Shared Functions. Cooperative activities would be conducted with industry personnel in program planning and development, curriculum development (deletion, addition, and modification), liaison with advisory committees, program evaluation, and research on student outcomes. These functions 
would be conducted on campus as part of the normal flow of events during the academic year in conjunction with professionals on loan from industry for a six- to twelve-month period. Industry staff would replace faculty undergoing retraining and would absorb full- or part-time teaching loads. They would also provide technical assistance in program planning and evaluation activities. Nagging questions related to resource development and the interface between education and work would also be addressed by industry professionals through cooperative activities with faculty and advisory committees on a program-by-program basis. A direct benefit of industry involvement in this phase would be the modernization of college curricula in accord with emerging technology. An indirect benefit would be preparation of the academic department for the return of retrained faculty from the industrial setting.

Industry Functions. Responsibility for faculty training and retraining activities would be assumed by industry in the industry/education exchange model. Selected faculty would be assigned full-time to industry for six- to twelve-month time periods to upgrade old skills and learn new skills. Once trained in new skills, faculty would contribute to the production capacity of industry through performance of skill functions on a full time basis. At the conclusion of the training period, faculty would return to the community college and replace industry personnel in the academic department.

A common problem in extant programs for faculty retraining in community colleges is the rigidity of the curriculum and academic organization which constrains the implementation of new ideas. Departments require preparation to receive retrained faculty from business and industry in order that new ideas and technical applications will not be wasted in tradition-bound programs. Direct industry involvement in program planning and evaluation activities will facilitate processes of curricular change and improve faculty receptivity to new ideas. The outcome will be a simultaneous cultivation of faculty knowledge of new industrial practices and technical applications through: 1) direct access to ideas in the industry setting and 2) indirect access to ideas through cooperative planning and evaluation activities with industry professionals in the institutional setting.

The industry-education exchange program is an efficient method to retrain faculty and simultaneously improve planning, evaluation, and resource development processes in community college career and technical programs. The basic task for any faculty retraining program is to improve the technical knowledge and teaching skills of faculty so that program quality can be improved to a level commensurate with student needs and industry standards. Academic departments which may have remained stagnant in a period of stable resources would have new sources of valuable information about the quality of their resources and products-there teaching faculty, curriculum organization, instructional strategies, equipment inventories, program planning and evaluation processes, academic support services, and student outcomes. Viewed through the eyes of industry personnel on loan to the institution in the exchange program, program deficiencies can be identified and corrective actions implemented to improve performance and prepare the department for 
the return of retrained faculty from industry. Similarly, understanding of respective industry and education roles in career training should improve as should industry appreciation of the problems and limitations experienced by community colleges in career education. Unless community colleges can develop systematic approaches to faculty retraining predicated on business and industry as a primary resource for development, the college cannot claim to produce direct benefits for students and industry. Entrenched career programs dependent on a core of faculty with outdated teaching skills make career education a cruel irony in community colleges.

\section{BIBLIOGRAPHY}

Bryan, James E., Jr. Future Faculty Employment Problems: A Community College Perspective, 31, Journal of the College and University Personnel Association, 56-60, Spring 1980.

Cohen, A.M., and Lombardi, J. "Can the Community Colleges Survive Success," Change, 1979, 11(8).

Cooperative Institutional Research Program. "Entering Freshman Characteristics," Graduate School of Education, University of California, Los Angeles, 1981.

Garlock, V. Faculty Development at Community Colleges: Who Participates. ED 168 621, 1979.

Lahti, R.E. "New Markets for Community Colleges," Community and Junior College Journal, 1977, 48(4).

Nelson, W., and Siegel, M., Eds. Effective Approaches to Faculty Development. ED $184349,1980$.

New York Times Survey of Continuing Education, August 30, 1981.

Rothman, J. Planning and Organizing for Social Change. Columbia University Press, New York, 1974.

Smith, P. "The New Professional: Professor or Facilitator?", in Serving Lifelong Learners. Heermann, B.; Enders, C.; and Wine, E. Eds, New Directions for Community Colleges, No. 29. 1980.

Vaughan, G. Questioning the Community College Role. New Directions for Community Colleges, No. 32, 1980.

Richard L. Alfred is Associate Professor of Higher Education and Director of the Community College Program, University of Michigan, Ann Arbor, Michigan.

Nancy S. Nash is a Ph.D. Candidate, Center for the Study of Higher Education, University of Michigan, Ann Arbor, Michigan. 